\title{
ERRATUM
}

Kunihiko Nomura $\cdot$ Yoshiaki Takei $\cdot$ Masaki Yoshida

Yasuyoshi Yanagida

\section{Phase-dependent chronotropic response of the heart during running in humans}

Published online: 21 April 2006

(c) Springer-Verlag 2006

\section{Eur J Appl Physiol (2006) \\ DOI 10.1007/s00421-005-0103-7}

The equation to obtain the instantaneous phase was described in the Data analyses section of the Methods of this article as $\phi(t)=2 \pi\left(t-t_{k} / t_{k+1}-t_{k}\right)+2 \pi k$. This equation should have been:

$\phi(t)=2 \pi \frac{t-t_{k}}{t_{k+1}-t_{k}}+2 \pi k$.

Furthermore, the equation to obtain the generalized relative phase was described in the Data analyses as $\Psi_{\text {a }}$ $-\mathrm{b}=1 / 2 \pi\left(\phi_{\mathrm{b}}\left(\mathrm{t}_{\mathrm{k}}\right) \bmod 2 \pi\right)$. This should have been as follows:

$\Psi_{\mathrm{a}-\mathrm{b}}=\frac{1}{2 \pi}\left(\phi_{\mathrm{b}}\left(t_{k}\right) \bmod 2 \pi\right)$.

The online version of the original article can be found at http:// dx.doi.org/10.1007/s00421-005-0103-7

K. Nomura $(\bowtie) \cdot M$. Yoshida

Department of Biomedical Engineering,

Osaka Electro-Communication University,

1130-70 Kiyotaki Shijonawate-shi, Osaka 575-0063, Japan

E-mail: n-kuni@isc.osakac.ac.jp

Tel.: + 81-72-8765185

Fax: + 81-72-8765199

Y. Takei $\cdot$ Y. Yanagida

Faculty of Human Development, Kobe University,

3-11 Tsurukabuto Nada-ku Kobe-shi, Hyougo 657-8501, Japan 